Braz J Med Biol Res, April 2012, Volume 45(4) 357-365

doi: $10.1590 / \mathrm{S} 0100-879 X 2012007500029$

Fine-tuning of defensive behaviors in the dorsal periaqueductal gray by atypical neurotransmitters

M.V. Fogaça, S.F. Lisboa, D.C. Aguiar, F.A. Moreira, F.V. Gomes, P.C. Casarotto and F.S. Guimarães

The Brazilian Journal of Medical and Biological Research is partially financed by

\section{惡CNPq}

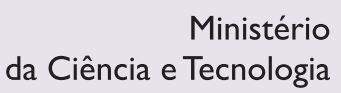

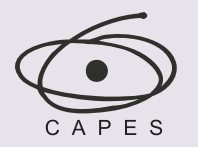

Ministério da Educação
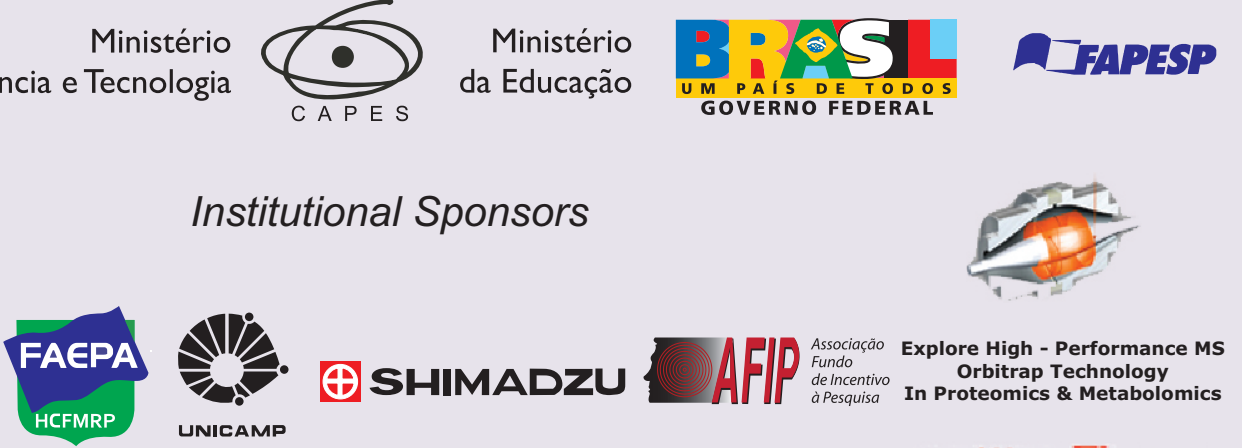

Institutional Sponsors

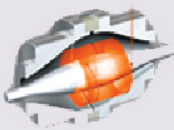

$\oplus$ SHIMADZU UNICAMP

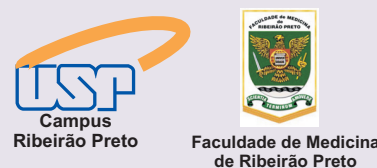
de Ribeirão Preto
de 


\title{
Fine-tuning of defensive behaviors in the dorsal periaqueductal gray by atypical neurotransmitters
}

\author{
M.V. Fogaça ${ }^{1}$, S.F. Lisboa ${ }^{1}$, D.C. Aguiar², F.A. Moreira², F.V. Gomes ${ }^{1}$, \\ P.C. Casarotto ${ }^{1}$ and F.S. Guimarães ${ }^{1}$ \\ ${ }^{1}$ Departamento de Farmacologia, Faculdade de Medicina de Ribeirão Preto, \\ Universidade de São Paulo, Ribeirão Preto, SP, Brasil \\ 2Departamento de Farmacologia, Instituto de Ciências Biológicas, \\ Universidade Federal de Minas Gerais, Belo Horizonte, MG, Brasil
}

\begin{abstract}
This paper presents an up-to-date review of the evidence indicating that atypical neurotransmitters such as nitric oxide (NO) and endocannabinoids (eCBs) play an important role in the regulation of aversive responses in the periaqueductal gray (PAG). Among the results supporting this role, several studies have shown that inhibitors of neuronal NO synthase or cannabinoid type 1 (CB1) receptor agonists cause clear anxiolytic responses when injected into this region. The nitrergic and eCB systems can regulate the activity of classical neurotransmitters such as glutamate and $y$-aminobutyric acid (GABA) that control PAG activity. We propose that they exert a 'fine-tuning' regulatory control of defensive responses in this area. This control, however, is probably complex, which may explain the usually bell-shaped dose-response curves observed with drugs that act on NO- or CB1-mediated neurotransmission. Even if the mechanisms responsible for this complex interaction are still poorly understood, they are beginning to be recognized. For example, activation of transient receptor potential vanilloid type-1 channel (TRPV1) receptors by anandamide seems to counteract the anxiolytic effects induced by CB1 receptor activation caused by this compound. Further studies, however, are needed to identify other mechanisms responsible for this fine-tuning effect.
\end{abstract}

Key words: Endocannabinoid; Anandamide; Nitric oxide; Endovanilloid; TRPV1

\section{Introduction}

The periaqueductal gray matter (PAG) is a midbrain structure that surrounds the Sylvius aqueduct and has been implicated in the modulation of cardiovascular and motor control, nociceptive information and defensive responses $(1,2)$. In laboratory animals, stimulation of the dorsal parts of the PAG leads to full-blown escape responses accompanied by sympathetic arousal (3). These escape reactions are attenuated by serotonin reuptake inhibitors (SSRIs) (4), first choice drugs in the treatment of several anxiety disorders.

The involvement of the PAG in defensive behaviors has also been supported by clinical studies. Electrical stimulation of the deep layers of the superior colliculus and periaqueductal gray matter in neurosurgery patients causes intense fear and a feeling of imminent death accompanied by autonomic changes such as increased blood pressure and heart rate (5). These responses are similar to those described for animals facing an imminent, proximal threat such as a predator. Accordingly, recent neuroimaging studies in healthy volunteers have shown that the dorsal part of the PAG is activated during the presentation of proximal threats (6).

On the basis of the similarity between these reactions and panic attacks, as well as on the pharmacological response to SSRIs, stimulation of the PAG has been proposed as a model of panic attack (4). Several lines of evidence support this proposal, indicating that the PAG, particularly its dorsal part, is a crucial structure in the defensive system (7).

\section{Classical neurotransmitters, the PAG and defensive behaviors}

Several neurotransmitters are present in the PAG, inter-

Correspondence: F.S. Guimarães, Departamento de Farmacologia, Faculdade de Medicina de Ribeirão Preto, USP, Av. Bandeirantes, 3900, 14049-900 Ribeirão Preto, SP, Brasil. E-mail: fsguimar@fmrp.usp.br

Presented at the III Fórum em Neurobiologia do Estresse, Araraquara, SP, Brazil, September 8-10, 2011.

Received December 17, 2011. Accepted February 23, 2012. Available online March 9, 2012. Published April 9, 2012. 
acting in a complex way to control defensive responses in this region (8-11). The main excitatory input to the PAG is glutamatergic, and glutamate receptors are widely distributed throughout this region (12). There is a vast literature demonstrating that intra-PAG administration of glutamate or an $\mathrm{N}$-methyl-D-aspartate (NMDA) glutamate receptor agonist promotes defensive responses $(13,14)$. On the other hand, direct injections of NMDA and non-NMDA receptor antagonists into the dorsal PAG (dPAG) induce anxiolytic-like effects in animal models such as the elevated plus maze (EPM) and the Vogel conflict test (VCT) (15-17). Metabotropic glutamate receptors (mGluR) in the dPAG could also play a role in anxiety modulation. For example, intra-dPAG administration of a group I and II mGluR agonist induced flight reactions, an effect attenuated by pretreatment with mGluR1 and mGluR5 antagonists (18).

Besides glutamatergic neurotransmission, drugs that mimic or enhance the effects of the inhibitory neurotransmitter $y$-amino-butyric-acid (GABA), such as the GABA-Aagonist muscimol or benzodiazepine receptor agonists, as well as those that facilitate serotoninergic transmission through the activation of 5 -hydroxytryptamine- $1 \mathrm{~A}\left(5-\mathrm{HT}_{1} \mathrm{~A}\right)$ or $5-\mathrm{HT}_{2}$ receptors, attenuate the aversive consequences of dPAG electrical stimulation and produce anxiolytic-like effects in animal models of anxiety (19-21). Moreover, whereas the intra-dPAG injections of serotonergic antagonists have no effect on defensive responses, the microinjection of GABA-A antagonists elicits, by itself, explosive escape reactions (21) similar to those induced by local electrical stimulation. These data suggest that GABAergic mechanisms tonically inhibit the PAG network that controls defensive behaviors, whereas serotonin exerts a phasic inhibition of this network.

Several neuropeptides have also been implicated in the generation and elaboration of defense responses mediated by the dPAG. For example, direct injections of corticotrophin-releasing hormone $(\mathrm{CRH})$, substance $\mathrm{P}$ or cholecystokinin (CCK) into the dPAG produce anxiogeniclike effects (22-24).

\section{Atypical neurotransmitters}

Several key discoveries made during the 80s and the early 90 s have established the concept of atypical neurotransmitters. These substances, contrary to classical neurotransmitters, are produced 'on demand' in and released from the postsynaptic neuronal membrane. Being highly liposoluble, they can act presynaptically to modify neurotransmitter release $(25,26)$. The two main atypical neurotransmitters are nitric oxide (NO) and the endocannabinoids (eCBs). NO is a short-lived gas produced from the amino acid l-arginine by a family of enzymes called NO synthases (NOS) (25). The neuronal NOS (nNOS) isoform is constitutive in the central nervous system (CNS) and located in specific brain regions. It is related to glutamate NMDA receptors and activated postsynaptically by calcium influx through these receptors (26).

The eCBs were isolated following the identification of a cannabinoid receptor now named CB1 and the subsequent search for endogenous ligands. The first recognized cannabinoid receptor agonist was arachidonoyl-ethanolamide, or anandamide (AEA) (27). Since then other endogenous CB1 agonists have been isolated. They include 2-arachidonoyl glycerol (2-AG), N-arachidonoyl dopamine, noladine, and virodhamine (27), all of them arachidonic acid derivatives (27).

Several lines of evidence indicate that these atypical neurotransmitters can modulate defensive behavior. For example, systemic administration of drugs that act on NOor eCB-mediated neurotransmission modify anxiety-like behavior in different animal models $(28,29)$. Moreover, both the nNOS enzyme and CB1 receptors have been located in key brain areas related to defensive behaviors, including the PAG (28-30).

\section{NO, PAG and defensive behavior}

In the PAG, nNOS-containing neurons are located specifically in the dorsolateral column (30). Local injections of NOS inhibitors or NO scavengers into this region induce anxiolytic-like effects in distinct animal models of anxiety that include the EPM, VCT and predator exposure $(29,31$ 33). In contrast, NO donors injected into the dorsolateral PAG (dIPAG) induced flight responses $(34,35)$ (Table 1). Additionally, studies using cFos immunohistochemistry as a tool to reveal neuronal activation show that different aversive conditions such as exposure to an EPM, restraint stress or a predator or ethanol withdrawal activates NOSpositive neurons in this region (36-39).

In the CNS, the effects of NO are exerted mainly through the activation of the soluble guanylate cyclase (sGC) enzyme leading to increased levels of cGMP (25). Accordingly, defensive behaviors induced by NO donors in the dIPAG depend on activation of local sGC, since these effects are attenuated by previous local injection of ODQ, a GC inhibitor (34). Moreover, a cGMP analogue (8-bromocGMP) injected into the dIPAG also induced fight/flight behavior similar to NO donors, with GC inhibitors inducing anxiolytic-like effects in animals exposed to the EPM and VCT $(28,33)$. In agreement with these results, Chiavegatto et al. (40) showed that exposure to a live cat increases the production of citrulline (an indirect index of NOS activity) and cGMP in the dIPAG in rats. Taken together, these results indicate that the effects of NO on the dIPAG are probably mediated by the sGC/cGMP pathway.

Since NO is a diffusible gas, it can modulate the effects of several neurotransmitters such as glutamate, GABA, $5-\mathrm{HT}, \mathrm{CCK}$, and cannabinoids (25) that have been related to the control of defensive behaviors in the PAG. As mentioned before, in the CNS there is reciprocal regulation between glutamate and $\mathrm{NO}$, since activation of nNOS is 
Table 1. Effects of nitric oxide-related drugs on defensive behavior when injected into the intradorsal periaqueductal gray region.

\begin{tabular}{llllll}
\hline Drug (dose) & Possible mechanism & Species & Animal model & Main effect & References \\
\hline Carboxy-PTIO $(0.3-3 \mathrm{nmol})$ & NO scavenger & Rat & VCT, EPM & Anxiolytic & $21,28^{*}, 33$ \\
& & & OA & No effect & \\
DEA/NO $(150-600 \mathrm{nmol})$ & NO donor & Rat & OA & Pro-aversive & 35 \\
L-NOARG $(10-100 \mathrm{nmol})$ & NOS inhibitor & Rat & EPM & Anxiolytic & $32^{*}$ \\
L-NAME $(100-200 \mathrm{nmol})$ & NOS inhibitor & Rat & EPM, T-maze & Anxiolytic & $31,32^{*}, 49$ \\
& & & OA & No effect & \\
Methylene blue $(10-100 \mathrm{nmol})$ & SGC and NOS inhibitor & Rat & EPM & Anxiolytic & $50^{*}$ \\
NOC-9 $(75-150 \mathrm{nmol})$ & NO donor & Rat & OA & Pro-aversive & 34 \\
NPA $(0.08-100 \mathrm{nmol})$ & Selective nNOS inhibitor & Rat, Mice & VCT, CET, RET & Anxiolytic & $33,36,51$ \\
SIN-1 $(150-300 \mathrm{nmol})$ & NO donor & Rat & OA & Pro-aversive & $28,34,35,45$ \\
ODQ $(0.3-3 \mathrm{nmol})$ & sGC inhibitor & Rat & EPM & Anxiolytic & $28^{*}, 31,52$ \\
& & & OA & No effect & 52 \\
$7 N I(40 \mathrm{nmol})$ & Preferential nNOS inhibitor & Rat & EPM & No effect & 52 \\
\hline
\end{tabular}

Drugs: Carboxy-PTIO = 2-(4-carboxyphenyl)-4,4,5,5-tetramethylimidazoline-1-oxyl-3-oxide potassium salt; DEA/NO = diethylamine NONOate; L-NOARG $=\mathrm{N}(\mathrm{G})$-nitro-L-arginine; L-NAME = N(G)-nitro-L-arginine methyl ester hydrochloride; NOC-9 = 6-(2-hydroxy-1-methyl-2-nitrosohydrazino)-N-methyl-1-hexanamine; NPA = n-propyl-L-arginine; SIN-1 = 3-(4-morpholinyl)sydnonimine; $\mathrm{ODQ}={ }^{1} \mathrm{H}$-[1,2,4] oxadiazolo[4,3-a]quinoxalin-1-one; 7-NI = 7-nitro-indazol. Mechanisms: $\mathrm{NO}=$ nitric oxide; $\mathrm{NOS}=$ NO synthase; $\mathrm{sGC}$ = soluble guanylyl cyclase; $\mathrm{nNOS}=$ neuronal NOS. Models: $\mathrm{VCT}$ = Vogel conflict test; $\mathrm{EPM}=$ elevated plusmaze; $\mathrm{OA}=$ open arena; $\mathrm{CET}$ = cat exposure test; $\mathrm{RET}$ = rat exposure test. *Indicates a bell-shaped dose-response curve.

dependent on $\mathrm{Ca}^{2+}$ influx induced by activation of NMDA receptors (25). Electrophysiological data showed that excitatory postsynaptic potentials induced by NO in dPAG slices are reduced by antagonists of ionotropic glutamate receptors (41). Reinforcing the possibility that NO effects in the PAG depend on facilitation of glutamate-mediated neurotransmission, we showed that local pretreatment with AP7, an NMDA receptor antagonist, blocked the aversivelike reaction induced by linsidomine chlorhydrate (SIN-1) (42) and reduced the activation of NOS neurons induced by predator exposure (36). More recently, we determined if the defensive reactions induced by NMDA in the dIPAG would depend of endogenous NO. Our experiments, performed with rats, showed that the escape responses induced by NMDA in the dIPAG are independent of endogenous NO (31). However, in mice these responses were prevented by a selective nNOS inhibitor $(43,44)$. This difference may be related to the different species or the doses of NMDA employed.

The aversive reactions of NO donors in the dIPAG could also be modulated by $5-\mathrm{HT}$ neurons, which are known to inhibit panic-like responses (21). Local injections of $5-\mathrm{HT}_{2 \mathrm{~A}}$ receptor agonists reduced the escape reaction induced by SIN-1, a nitric oxide donor (45). Moreover, intradorsal raphe nucleus administration of the $5-\mathrm{HT}_{1 \mathrm{~A}}$ receptor agonist, 8-OH-DPAT, which inhibits the activity of $5-\mathrm{HT}$ neurons, favored the expression of escape induced by SIN-1 in the dPAG (46). The effects of 5-HT on flight responses induced by SIN-1 may involve indirect GABAergic facilitation, since $5-\mathrm{HT}_{2}$ receptors are co-expressed in GABAergic neurons
(8). In agreement with these results, defensive-like responses induced by intra-dIPAG administration of SIN-1 were attenuated by midazolam, a benzodiazepine receptor agonist (47).

It is also possible that the effects of NO on the PAG involve a direct interference with GABA-mediated neurotransmission, since GABA-expressing neurons in the dIPAG are co-expressed with nNOS-positive neurons (8). Moreover, electrophysiological studies performed in dIPAG slices showed that $\mathrm{NO}$ can potentiate the synaptic release of GABA (48).

\section{eCB, PAG and defensive behavior}

In the PAG, eCBs, similar to NO, modulate the release of several neurotransmitters that regulate defensive behaviors $(29,53)$. CB1 receptors and the fatty acid amide hydrolase (FAAH) enzyme, responsible for AEA degradation, are complementarily expressed along the PAG (54). Moreover, systemic or intracerebroventricular administration of CB1 agonists increases cFos expression in the PAG (55) and AEA and 2-AG levels increase in this region after exposure to aversive footshock stress (56). Taken together, these lines of evidence indicate that eCBs could also be related to defensive reactions in this region. Accordingly, local administration of the synthetic cannabinoid HU210 attenuated defensive behaviors induced by either intra-dPAG injection of excitatory amino acid or by ultrasound exposure $(57,58)$ and intra-PAG administration of drugs that increase eCBsignaling potentiates stress-induced analgesia (56). 
In an attempt to better understand the involvement of eCBs in defensive behaviors controlled by the dIPAG, our group showed that local injection of AEA induces anxiolyticlike effect in animals exposed to the EPM through activation of $\mathrm{CB} 1$ receptors (59). Anxiolytic-like effects were mimicked by arachidonoylchloroethanolamide (ACEA), a selective $C B 1$ agonist, and potentiated by the inhibitor of $A E A$ transport, AM404. However, as frequently observed after systemic injections, AEA and ACEA produced a bell-shaped dose-response curve, with the higher doses being ineffective (59). Moreover, intra-dIPAG-administered AM404 by itself failed to cause any effect in the EPM (59) (Table 2).

These anxiolytic-like effects of AEA in the dIPAG were subsequently confirmed in two other animal models of anxiety, the VCT and contextual fear conditioning test (CFC) $(60,61)$. Different from the EPM, however, in these studies drugs that inhibit AEA uptake/metabolism induced anxiolytic-like effects. One possible interpretation for this discrepancy is that the eCB system in the PAG is more intensely recruited under higher stress situations, such as those that involve aversive electrical shocks like the VCT and CFC. Accordingly, in CB1 knockout mice the light intensity in the behavioral test room was shown to be a crucial factor to determine the levels of anxiety of the animals (62).
The role of the eCB system in defensive behaviors mediated by the PAG was more recently investigated in two panic models, predator (cat) exposure and electrical stimulation of the dPAG. As observed previously in anxiety models, intra-dIPAG injection of AEA induced antiaversive effects in both models (63, and Lisboa SF and Guimaraes FS, unpublished results). Taken together, these results strongly suggest that eCBs play an important modulatory role in the defensive behaviors mediated by the PAG. This role could involve regulation of glutamate-mediated neurotransmission, since cannabinoid agonists have been shown to inhibit glutamatergic synaptic transmission in this region (64). Interaction with mGluR could also be important. In the PAG activation of mGluR, subtype 5 (mGluR5) induces the release of eCBs, which, in turn, activate presynaptic cannabinoid CB1 and cause analgesia (65).

eCBS can also change GABAergic neurotransmission in the PAG. Local blockade of GABA receptors attenuates cannabinoid-induced sympathoexcitation and pressor responses, suggesting that eCBs could facilitate sympathetic activation by disruption of GABAergic neurotransmission in the PAG (66). It remains to be confirmed if interference with GABA-related mechanisms is involved in the bell-shaped dose-response curves observed when CB1 agonists are injected into the PAG (59).

Table 2. Effects of cannabinoid- and vanilloid-related drugs on defensive behavior when injected into the intradorsal periaqueductal gray region.

\begin{tabular}{|c|c|c|c|c|c|}
\hline Drug (dose) & Possible mechanism & Species & Animal model & Main effect & References \\
\hline ACEA $(0.01-5 \mathrm{pmol})$ & CB1/TRPV1 agonist & Rat & $\begin{array}{l}\text { EPM } \\
\text { EsES }\end{array}$ & $\begin{array}{l}\text { Anxiolytic } \\
\text { Panicolytic }\end{array}$ & $59^{*}, 63$ \\
\hline AEA (0.5-50 pmol) & CB1/TRPV1 agonist & Rat & $\begin{array}{l}\text { EPM, VCT } \\
\text { CFC }\end{array}$ & $\begin{array}{l}\text { Anxiolytic } \\
\downarrow C E R\end{array}$ & $59^{*}, 60,61$ \\
\hline AM251 (10-100 pmol) & CB1 antagonist & Rat & EPM, VCT & No effect & $59,60,67$ \\
\hline AM404 (50 pmol) & AEA uptake/metabolism inhibitor & Rat & $\begin{array}{l}\text { VCT } \\
\text { CFC }\end{array}$ & $\begin{array}{l}\text { Anxiolytic } \\
\downarrow C E R\end{array}$ & 60,61 \\
\hline Capsazepine (0.1-60 nmol) & TRPV1 antagonist & Rat & $\begin{array}{l}\text { EPM, VCT } \\
\text { EsES }\end{array}$ & $\begin{array}{l}\text { Anxiolytic } \\
\text { Panicolytic }\end{array}$ & 63,64 \\
\hline Capsaicin (0.01-1 nmol) & TRPV1 agonist & Rat & EsES & Anxiolytic & 69 \\
\hline CBD (10-60 nmol) & $5-\mathrm{HT}_{1 \mathrm{~A}}$ agonist & Rat & $\begin{array}{l}\text { EPM, ETM } \\
\text { EsES }\end{array}$ & $\begin{array}{l}\text { Anxiolytic } \\
\text { Panicolytic }\end{array}$ & $67^{*}$ \\
\hline HU210 (0.25-12.9 nmol) & CB1 agonist & Rat & EsCS, EsUs & Antiaversive & 57,58 \\
\hline SB366791 (10 nmol) & TRPV1 selective antagonist & Rat & EsES & Panicolytic & 63 \\
\hline URB597 (0.01 nmol) & AEA metabolism inhibitor & Rat & VCT & Anxiolytic & 60 \\
\hline WIN55,212-2 (3-30 pmol) & CB1/TRPV1 agonist & Rat & EPM & Anxiolytic & 68 \\
\hline
\end{tabular}

Drugs: $\mathrm{ACEA}$ = arachidonoylchloroethanolamide; $\mathrm{AEA}=$ anandamide; $\mathrm{CBD}=$ cannabidiol. Mechanisms: $\mathrm{CB} 1=$ cannabinoid receptor type 1; TRPV1 = transient receptor potential vanilloid type-1 channel; 5-HT $1 \mathrm{~A}=5$-hydroxytryptamine-1A. Models: EPM = elevated plus-maze; EsES = escape induced by dPAG electrical stimulation; VCT = Vogel conflict test; $C F C=$ contextual fear conditioning; ETM = elevated T-maze; EsCS = escape induced by dPAG chemical stimulation; EsUs: escape induced by ultrasound. Effects: CER = conditioned emotional response. ${ }^{*}$ Indicates a bell-shaped dose-response curve. 


\section{Endovanilloids, PAG and defensive behaviors}

Initially identified in the periphery as a receptor for the pungent ingredient of red-hot chili peppers, capsaicin, the transient receptor potential vanilloid type-1 channel (TRPV1) is also expressed in the CNS, where it can elevate calcium levels and potentiate synaptic transmission (29). Anandamide, together with $\mathrm{N}$-arachidonoyldopamine, $\mathrm{N}$-oleoylethanolamine and hydroperoxyeicosatetraenoic acids, has been proposed as one of its putative endogenous agonists, called endovanilloids (29).

The dual action of AEA as an agonist of CB1 and TRPV1 receptors has been related to the dual effects of this and other cannabinoids in several areas, including the PAG $(63,70)$. TRPV1 receptors are expressed in this and other regions related to the control of defensive responses (71). In the PAG, electrophysiological studies have shown that capsaicin, a TRPV1 receptor agonist, facilitates the release of glutamate by a presynaptic mechanism, indicating that these receptors are functional in this region (72). Several other studies, however, have also indicated a postsynaptic localization of TRPV1 receptors in forebrain limbic regions (73).

Although there are few studies in the literature investigating the effects of TRPV1-selective agonists on PAG-mediated defensive behaviors, direct microinjection of antagonists into this region suggests that the endovanilloid system plays an important role in modulating these behaviors (see Table 2). For example, intra-dPAG injection of TRPV1 antagonists such as capsazepine and SB366791 caused anxiolytic- and panicolytic-like effects, respectively, in different animal models $(63,64)$.

These results suggest that TRPV 1 receptors are tonically activated by endovanilloids such as anandamide, facilitating vanilloid-mediated defensive responses. However, another possibility to explain these results is an interaction between the endovanilloid and endocannabinoid systems, in a way that the presence of TRPV1 antagonists allows for a selective anandamide effect, redirecting its action entirely to CB1 receptors (63).

Supporting this proposal, activation of TRPV1 receptors has been related to the bell-shaped dose-response curves usually produced by cannabinoid compounds. It was demonstrated, for example, that whereas the anxiolyticlike effect of intra-dPAG administration of the anandamide analogue ACEA is mediated by CB1 receptors, the loss of this response seen with higher ACEA doses is reversed when the animals are pretreated with TRPV1 antagonists (63). Similar effects were demonstrated for the synthetic cannabinoid WIN55,212-2 (that can also activate CB1 and TRPV1 receptors) and the non-psychotomimetic phytocannabinoid cannabidiol $(67,68)$. Although the latter compound has a complex pharmacology, at high doses it can activate TRPV1 receptors (67).
Contrasting with these results, dIPAG-injection of the TRPV1 agonist capsaicin induced anxiolytic-like effects in rats submitted to the EPM and VCT (64). Studies in peripheral tissues, however, have shown that this drug can induce a rapid desensitization of TRPV1 receptors (74). At present it is still unclear, however, if a similar mechanism occurs in the PAG.

\section{Possible interactions between atypical neurotransmitters in the control of defensive behaviors}

Several in vitro studies (75-78) have suggested a functional interaction between the cannabinoid and nitrergic systems in the CNS and peripheral tissues. This possible interaction involves different components of these two systems. For example, studies with endothelial cells and synaptosomes derived from rat brain, as well as an ex-vivo model of blood-brain barrier, suggest that $\mathrm{NO}$ can control the activity of the proposed AEA transporter (77).

Stimulation of CB1 receptors by different cannabinoid agonists enhances nNOS activity, increasing the production of cGMP $(75,76)$. This effect is involved in some in vivo cannabinoid effects such as AEA-induced inhibition of depolarization-evoked dopamine release in leech ganglia and stimulation of neuropeptide release from the mammalian median eminence $(77,79)$. Also, the usual development of tolerance to the acute hypothermic and cataleptic effects observed with cannabinoid agonists such as WIN55,2122 is prevented by repeated administration of L-NAME, a non-specific NOS inhibitor (80). Corroborating this finding, some acute effects of tetrahydrocannabinol (THC), including hypolocomotion and hypothermia, are decreased in nNOS knockout mice. This same study demonstrated that several nNOS-positive neurons co-express CB1 receptors in the caudate-putamen and hypothalamus, two brain regions related to motor and temperature control, respectively (81).

Although these studies indicate that CB1 activation can induce NO production, opposite results have been reported. For example, the potent CB1 agonist CP-55,940 was able to decrease $\mathrm{NO}$ release in microglial cells stimulated with an endotoxin (82) and L-NAME increased the central hypothermic effect of the CB1 agonist WIN55,212-2 in rats (83). In addition, in cultures of rat cerebellar granule cells, depolarization-induced $\mathrm{Ca}^{2+}$ influx and subsequent NOS activation were reduced by WIN55,212-2 through inhibition of voltage-gated $\mathrm{Ca}^{2+}$ channels (84). Moreover, animals that lack the CB1 gene present an increase in NOS activity in the cerebral cortex, suggesting that CB1 is required to inhibit this activity (85). These results suggest that the interaction between CB1 and NOS activation is complex, with the former, under certain conditions, counteracting some effects of NO.

In the dIPAG, as mentioned earlier, NOS inhibitors, NO scavengers and SGC inhibitors cause anxiolytic-like effects 
in animal models (28), whereas NO donors induce flight reactions $(28,34)$. The latter responses are prevented by local pretreatment with NMDA and non-NMDA glutamate receptor antagonists, suggesting, as shown elsewhere (25), that the effects of NO donors in the dIPAG are mediated by facilitation of glutamate release. As seen, CB1 receptors are also present in the PAG (54) where they can decrease glutamate release (64). This mechanism could explain the similar anxiolytic effects found after intra-dIPAG administration of CB1 receptor agonists (59-61) and glutamate ionotropic receptor antagonists $(15,16)$.

Since NO and eCBs can regulate, usually in opposite directions, the release of neurotransmitters such as glutamate and GABA, and based on the several lines of evidence discussed above indicating that these two systems regulate defensive responses, we determined if they interact in the dIPAG to modulate these responses. In agreement with this proposal, low doses of AEA or an FAAH inhibitor administered into the dIPAG attenuated the flight responses induced by an NO donor, suggesting that activation of CB1 receptors could decrease $\mathrm{NO}$-induced glutamate release. Also, the CB1 receptor antagonistAM251 not only prevented the effects of AEA but also increased the effect of NO (86). The latter effect could involve TRPV1 receptors since, as discussed before, in the PAG CB1 and TRPV1 receptors can be simultaneously activated at a given synapse to modulate defensive-like responses (63). Activation of TRPV1 has also been shown to promote NO formation in endothelial cells and in the placenta $(87,88)$ and capsazepine was able to decrease the defensive reactions induced by an NO donor effect in the dIPAG (Aguiar DC and Guimaraes FS, unpublished results).

In the PAG activation, presynaptic TRPV1 receptor has been shown to increase glutamate release (72). However, it is possible that postsynaptic receptors are also involved. This has been recently observed by Zschenderlein et al. (89) in another brain region related to defensive responses, the lateral amygdala. They showed that, after high frequency stimulation, capsaicin activates postsynaptic TRPV1 receptors. This could activate $\mathrm{nNOS}$ and increase NO production by facilitating $\mathrm{Ca}^{2+}$ entry, resulting in presynaptic glutamate

\section{References}

1. Bandler R, Shipley MT. Columnar organization in the midbrain periaqueductal gray: modules for emotional expression? Trends Neurosci 1994; 17: 379-389.

2. Behbehani MM. Functional characteristics of the midbrain periaqueductal gray. Prog Neurobiol 1995; 46: 575-605.

3. Schenberg LC, Bittencourt AS, Sudre EC, Vargas LC. Modeling panic attacks. Neurosci Biobehav Rev 2001; 25: 647-659.

4. Schenberg LC. Towards a translational model of panic attack. Psychology Neurosci 2010; 3: 9-37.

5. Nashold BS Jr, Wilson WP, Slaughter DG. Sensations release and enhancement of long-term potentiation (LTP). At low frequency stimulation, on the other hand, postsynaptic TRPV1 activation could induce AEA synthesis, which in turn activates presynaptic CB1 receptors, reducing glutamate release and inhibiting LTP. It remains to be determined if similar mechanisms occur in the PAG.

\section{Conclusions}

The studies reviewed above clearly indicate that, in addition to classical neurotransmitters such as glutamate, GABA, serotonin, and neuropeptides, atypical transmitter molecules can also regulate defensive responses in the dIPAG.

Since these transmitters, which include NO, endocannabinoids and endovanilloids, exert most of their effects by modulating the release and/or effects of these classical neurotransmitters, they also play a 'fine-tuning' regulatory role in these responses. Several pharmacological results obtained in this region, together with a few electrophysiological and microdialysis data, indicate that this 'fine-tuning' role involves glutamate-mediated neurotransmission. At low doses AEA could activate CB1 receptors and attenuate defensive behaviors by decreasing glutamate release, while at higher doses it becomes ineffective or even increases these responses by also activating TRPV1 receptors and facilitating glutamate release. $\mathrm{NO}$, on the other hand, may also participate in this fine-tuning role by increasing glutamate release. In addition, NO formation would also be modulated in a dual way by AEA through activation of CB1 and TRPV1 receptors.

Although these results have mostly focused on glutamate, based on what has been described in other brain regions, it is most reasonable that other neurotransmitters such as GABA and serotonin are also involved in the effects of these atypical transmitters. This issue needs to be further investigated in future studies.

\section{Acknowledgments}

We thank FAPESP and CNPq for financial support. evoked by stimulation in the midbrain of man. $J$ Neurosurg 1969; 30: 14-24.

6. Mobbs D, Petrovic P, Marchant JL, Hassabis D, Weiskopf N, Seymour B, et al. When fear is near: threat imminence elicits prefrontal-periaqueductal gray shifts in humans. Science 2007; 317: 1079-1083.

7. Canteras NS, Resstel LB, Bertoglio LJ, Carobrez AP, Guimaraes FS. Neuroanatomy of anxiety. Curr Top Behav Neurosci 2010; 2: 77-96.

8. Griffiths JL, Lovick TA. Co-localization of $5-\mathrm{HT}_{2 \mathrm{~A}}$-receptorand GABA-immunoreactivity in neurones in the periaq- 
ueductal grey matter of the rat. Neurosci Lett 2002; 326: 151-154.

9. Moraes CL, Bertoglio LJ, Carobrez AP. Interplay between glutamate and serotonin within the dorsal periaqueductal gray modulates anxiety-related behavior of rats exposed to the elevated plus-maze. Behav Brain Res 2008; 194: 181186.

10. Brandao ML, Anseloni VZ, Pandossio JE, De Araujo JE, Castilho VM. Neurochemical mechanisms of the defensive behavior in the dorsal midbrain. Neurosci Biobehav Rev 1999; 23: 863-875.

11. Lovick TA. Panic disorder - a malfunction of multiple transmitter control systems within the midbrain periaqueductal gray matter? Neuroscientist 2000; 6: 48-59.

12. Tolle TR, Berthele A, Zieglgansberger W, Seeburg PH, Wisden W. The differential expression of 16 NMDA and non-NMDA receptor subunits in the rat spinal cord and in periaqueductal gray. J Neurosci 1993; 13: 5009-5028.

13. Bandler R, Carrive P. Integrated defence reaction elicited by excitatory amino acid microinjection in the midbrain periaqueductal grey region of the unrestrained cat. Brain Res 1988; 439: 95-106.

14. Bertoglio LJ, Zangrossi H Jr. Involvement of dorsolateral periaqueductal gray $\mathrm{N}$-methyl-D-aspartic acid glutamate receptors in the regulation of risk assessment and inhibitory avoidance behaviors in the rat elevated T-maze. Behav Pharmacol 2006; 17: 589-596.

15. Guimaraes FS, Carobrez AP, De Aguiar JC, Graeff FG. Anxiolytic effect in the elevated plus-maze of the NMDA receptor antagonist AP7 microinjected into the dorsal periaqueductal grey. Psychopharmacology 1991; 103: 91-94.

16. Molchanov ML, Guimaraes FS. Anxiolytic-like effects of AP7 injected into the dorsolateral or ventrolateral columns of the periaqueductal gray of rats. Psychopharmacology 2002; 160: 30-38.

17. Matheus MG, Guimaraes FS. Antagonism of non-NMDA receptors in the dorsal periaqueductal grey induces anxiolytic effect in the elevated plus maze. Psychopharmacology 1997; 132: 14-18.

18. Lima VC, Molchanov ML, Aguiar DC, Campos AC, Guimaraes FS. Modulation of defensive responses and anxiety-like behaviors by group I metabotropic glutamate receptors located in the dorsolateral periaqueductal gray. Prog Neuropsychopharmacol Biol Psychiatry 2008; 32: 178185.

19. Russo AS, Guimaraes FS, De Aguiar JC, Graeff FG. Role of benzodiazepine receptors located in the dorsal periaqueductal grey of rats in anxiety. Psychopharmacology 1993; 110: 198-202.

20. de Paula Soares V, Zangrossi H Jr. Involvement of 5-HT1A and $5-\mathrm{HT} 2$ receptors of the dorsal periaqueductal gray in the regulation of the defensive behaviors generated by the elevated T-maze. Brain Res Bull 2004; 64: 181-188.

21. Graeff FG, Brandao ML, Audi EA, Schutz MT. Modulation of the brain aversive system by GABAergic and serotonergic mechanisms. Behav Brain Res 1986; 22: 173-180.

22. Aguiar MS, Brandao ML. Effects of microinjections of the neuropeptide substance $P$ in the dorsal periaqueductal gray on the behaviour of rats in the plus-maze test. Physiol Behav 1996; 60: 1183-1186.

23. Netto CF, Guimaraes FS. Anxiogenic effect of cholecystokinin in the dorsal periaqueductal gray. Neuropsychopharma- cology 2004; 29: 101-107.

24. Litvin Y, Pentkowski NS, Blanchard DC, Blanchard RJ. CRF type 1 receptors in the dorsal periaqueductal gray modulate anxiety-induced defensive behaviors. Horm Behav 2007; 52: 244-251.

25. Esplugues JV. NO as a signalling molecule in the nervous system. Br J Pharmacol 2002; 135: 1079-1095.

26. Piomelli $D$. The molecular logic of endocannabinoid signalling. Nat Rev Neurosci 2003; 4: 873-884.

27. Howlett AC, Barth F, Bonner TI, Cabral G, Casellas P, Devane WA, et al. International Union of Pharmacology. XXVII. Classification of cannabinoid receptors. Pharmacol Rev 2002; 54: 161-202.

28. Guimaraes FS, Beijamini V, Moreira FA, Aguiar DC, de Lucca AC. Role of nitric oxide in brain regions related to defensive reactions. Neurosci Biobehav Rev 2005; 29: 1313-1322.

29. Moreira FA, Aguiar DC, Resstel LB, Lisboa SF, Campos AC, Gomes FV, et al. Neuroanatomical substrates involved in cannabinoid modulation of defensive responses. J Psychopharmacol 2012; [DOI: 10.1177/0269881111400651].

30. Vincent SR, Kimura H. Histochemical mapping of nitric oxide synthase in the rat brain. Neuroscience 1992; 46: 755-784.

31. Aguiar DC, Moreira FA, Guimaraes FS. Flight reactions induced by injection of glutamate $\mathrm{N}$-methyl-d-aspartate receptor agonist into the rat dorsolateral periaqueductal gray are not dependent on endogenous nitric oxide. Pharmacol Biochem Behav 2006; 83: 296-301.

32. Guimaraes FS, De Aguiar JC, Del Bel EA, Ballejo G. Anxiolytic effect of nitric oxide synthase inhibitors microinjected into the dorsal central grey. Neuroreport 1994; 5: 19291932.

33. Tonetto LL, Terzian AL, Del Bel EA, Guimaraes FS, Resstel LB. Inhibition of the NMDA receptor/nitric oxide pathway in the dorsolateral periaqueductal gray causes anxiolytic-like effects in rats submitted to the Vogel conflict test. Behav Brain Funct 2009; 5: 40.

34. Braga AA, Aguiar DC, Guimaraes FS. NOC-9, a selective nitric oxide donor, induces flight reactions in the dorsolateral periaqueductal gray of rats by activating soluble guanylate cyclase. Neurosci Lett 2009; 459: 79-83.

35. de Oliveira RW, Del Bel EA, Guimaraes FS. Behavioral and c-fos expression changes induced by nitric oxide donors microinjected into the dorsal periaqueductal gray. Brain Res Bull 2000; 51: 457-464.

36. Aguiar DC, Guimaraes FS. Blockade of NMDA receptors and nitric oxide synthesis in the dorsolateral periaqueductal gray attenuates behavioral and cellular responses of rats exposed to a live predator. J Neurosci Res 2009; 87: 24182429.

37. Beijamini V, Guimaraes FS. Activation of neurons containing the enzyme nitric oxide synthase following exposure to an elevated plus maze. Brain Res Bull 2006; 69: 347-355.

38. Beijamini V, Guimaraes FS. c-Fos expression increase in NADPH-diaphorase positive neurons after exposure to a live cat. Behav Brain Res 2006; 170: 52-61.

39. Bonassoli VT, Milani H, de Oliveira RM. Ethanol withdrawal activates nitric oxide-producing neurons in anxiety-related brain areas. Alcohol 2011; 45: 641-652.

40. Chiavegatto S, Scavone C, Canteras NS. Nitric oxide synthase activity in the dorsal periaqueductal gray of rats expressing innate fear responses. Neuroreport 1998; 9: 
571-576.

41. Hall CW, Behbehani MM. Synaptic effects of nitric oxide on enkephalinergic, GABAergic, and glutamatergic networks of the rat periaqueductal gray. Brain Res 1998; 805: 69-87.

42. Moreira FA, Molchanov ML, Guimaraes FS. Ionotropic glutamate-receptor antagonists inhibit the aversive effects of nitric oxide donor injected into the dorsolateral periaqueductal gray of rats. Psychopharmacology 2004; 171: 199-203.

43. Miguel TT, Nunes-de-Souza RL. Defensive-like behaviors and antinociception induced by NMDA injection into the periaqueductal gray of mice depend on nitric oxide synthesis. Brain Res 2006; 1076: 42-48.

44. Miguel TT, Nunes-de-Souza RL. Anxiogenic-like effects induced by NMDA receptor activation are prevented by inhibition of neuronal nitric oxide synthase in the periaqueductal gray in mice. Brain Res 2008; 1240: 39-46.

45. Moreira FA, Guimaraes FS. Role of serotonin receptors in panic-like behavior induced by nitric oxide in the rat dorsolateral periaqueductal gray: effects of chronic clomipramine treatment. Life Sci 2005; 77: 1972-1982.

46. Miguel TL, Pobbe RL, Spiacci Junior A, Zangrossi Junior H. Dorsal raphe nucleus regulation of a panic-like defensive behavior evoked by chemical stimulation of the rat dorsal periaqueductal gray matter. Behav Brain Res 2010; 213: 195-200.

47. Moreira FA, Guimaraes FS. Benzodiazepine receptor and serotonin $2 \mathrm{~A}$ receptor modulate the aversive-like effects of nitric oxide in the dorsolateral periaqueductal gray of rats. Psychopharmacology 2004; 176: 362-368.

48. Xing J, Li DP, Li J. Role of GABA receptors in nitric oxide inhibition of dorsolateral periaqueductal gray neurons. Neuropharmacology 2008; 54: 734-744.

49. Calixto AV, Duarte FS, Moraes CK, Faria MS, De Lima TC. Nitric oxide involvement and neural substrates of the conditioned and innate fear as evaluated in the T-maze test in rats. Behav Brain Res 2008; 189: 341-349.

50. de-Oliveira RW, Guimaraes FS. Anxiolytic effect of methylene blue microinjected into the dorsal periaqueductal gray matter. Braz J Med Biol Res 1999; 32: 1529-1532.

51. Carvalho-Netto EF, Gomes KS, Amaral VC, Nunes-deSouza RL. Role of glutamate NMDA receptors and nitric oxide located within the periaqueductal gray on defensive behaviors in mice confronted by predator. Psychopharmacology 2009; 204: 617-625.

52. Morato GS, Ortiga RM, Ferreira VM. Involvement of nitric oxide-dependent pathways of dorsolateral periaqueductal gray in the effects of ethanol in rats submitted to the elevated plus-maze test. Behav Brain Res 2004; 153: 341-349.

53. Moreira FA, Aguiar DC, Campos AC, Lisboa SF, Terzian AL, Resstel LB, et al. Antiaversive effects of cannabinoids: is the periaqueductal gray involved? Neural Plast 2009; 2009: 625469.

54. Egertova M, Cravatt BF, Elphick MR. Comparative analysis of fatty acid amide hydrolase and $\mathrm{cb}(1)$ cannabinoid receptor expression in the mouse brain: evidence of a widespread role for fatty acid amide hydrolase in regulation of endocannabinoid signaling. Neuroscience 2003; 119: 481-496.

55. McGregor IS, Arnold JC, Weber MF, Topple AN, Hunt GE. A comparison of delta 9-THC and anandamide induced c-fos expression in the rat forebrain. Brain Res 1998; 802: 1926.

56. Hohmann AG, Suplita RL, Bolton NM, Neely MH, Fegley
$D$, Mangieri $R$, et al. An endocannabinoid mechanism for stress-induced analgesia. Nature 2005; 435: 1108-1112.

57. Finn DP, Jhaveri MD, Beckett SR, Kendall DA, Marsden CA, Chapman V. Cannabinoids modulate ultrasound-induced aversive responses in rats. Psychopharmacology 2004; 172 : 41-51.

58. Finn DP, Jhaveri MD, Beckett SR, Roe CH, Kendall DA, Marsden CA, et al. Effects of direct periaqueductal grey administration of a cannabinoid receptor agonist on nociceptive and aversive responses in rats. Neuropharmacology 2003; 45: 594-604.

59. Moreira FA, Aguiar DC, Guimaraes FS. Anxiolytic-like effect of cannabinoids injected into the rat dorsolateral periaqueductal gray. Neuropharmacology 2007; 52: 958-965.

60. Lisboa SF, Resstel LB, Aguiar DC, Guimaraes FS. Activation of cannabinoid CB1 receptors in the dorsolateral periaqueductal gray induces anxiolytic effects in rats submitted to the Vogel conflict test. Eur J Pharmacol 2008; 593: 73-78.

61. Resstel LB, Lisboa SF, Aguiar DC, Correa FM, Guimaraes FS. Activation of CB1 cannabinoid receptors in the dorsolateral periaqueductal gray reduces the expression of contextual fear conditioning in rats. Psychopharmacology 2008; 198: 405-411.

62. Jacob W, Yassouridis A, Marsicano G, Monory K, Lutz B, Wotjak CT. Endocannabinoids render exploratory behaviour largely independent of the test aversiveness: role of glutamatergic transmission. Genes Brain Behav 2009; 8: 685-698.

63. Casarotto PC, Terzian AL, Aguiar DC, Zangrossi H, Guimaraes FS, Wotjak CT, et al. Opposing roles for cannabinoid receptor type-1 (CB(1)) and transient receptor potential vanilloid type-1 channel (TRPV1) on the modulation of panic-like responses in rats. Neuropsychopharmacology 2012; 37: 478-486.

64. Vaughan CW, Connor M, Bagley EE, Christie MJ. Actions of cannabinoids on membrane properties and synaptic transmission in rat periaqueductal gray neurons in vitro. Mol Pharmacol 2000; 57: 288-295.

65. Palazzo E, de Novellis V, Marabese I, Cuomo D, Rossi F, Berrino L, et al. Interaction between vanilloid and glutamate receptors in the central modulation of nociception. Eur $J$ Pharmacol 2002; 439: 69-75.

66. Dean C. Cannabinoid and GABA modulation of sympathetic nerve activity and blood pressure in the dorsal periaqueductal gray of the rat. Am J Physiol Regul Integr Comp Physiol 2011; 301: R1765-R1772.

67. Campos AC, Guimaraes FS. Involvement of 5HT1A receptors in the anxiolytic-like effects of cannabidiol injected into the dorsolateral periaqueductal gray of rats. Psychopharmacology 2008; 199: 223-230.

68. Campos AC, Guimaraes FS. Evidence for a potential role for TRPV1 receptors in the dorsolateral periaqueductal gray in the attenuation of the anxiolytic effects of cannabinoids. Prog Neuropsychopharmacol Biol Psychiatry 2009; 33: 1517-1521.

69. Terzian AL, Aguiar DC, Guimaraes FS, Moreira FA. Modulation of anxiety-like behaviour by transient receptor potential vanilloid type 1 (TRPV1) channels located in the dorsolateral periaqueductal gray. Eur Neuropsychopharmacol 2009; 19: 188-195.

70. Moreira FA, Aguiar DC, Terzian AL, Guimaraes FS, Wotjak CT. Cannabinoid type 1 receptors and transient receptor po- 
tential vanilloid type 1 channels in fear and anxiety-two sides of one coin? Neuroscience 2011; [http://dx.doi.org/10.1016/j. neuroscience.2011.08.046].

71. Cristino L, De Petrocellis L, Pryce G, Baker D, Guglielmotti V, Di Marzo V. Immunohistochemical localization of cannabinoid type 1 and vanilloid transient receptor potential vanilloid type 1 receptors in the mouse brain. Neuroscience 2006; 139: 1405-1415.

72. Xing J, Li J. TRPV1 receptor mediates glutamatergic synaptic input to dorsolateral periaqueductal gray (dl-PAG) neurons. J Neurophysiol 2007; 97: 503-511.

73. Puente N, Cui Y, Lassalle O, Lafourcade M, Georges F, Venance $\mathrm{L}$, et al. Polymodal activation of the endocannabinoid system in the extended amygdala. Nat Neurosci 2011; 14: 1542-1547.

74. Szallasi A, Blumberg PM. Vanilloid (Capsaicin) receptors and mechanisms. Pharmacol Rev 1999; 51: 159-212.

75. Carney ST, Lloyd ML, MacKinnon SE, Newton DC, Jones JD, Howlett AC, et al. Cannabinoid regulation of nitric oxide synthase I (nNOS) in neuronal cells. J Neuroimmune Pharmacol 2009; 4: 338-349.

76. Jones JD, Carney ST, Vrana KE, Norford DC, Howlett AC. Cannabinoid receptor-mediated translocation of NOsensitive guanylyl cyclase and production of cyclic GMP in neuronal cells. Neuropharmacology 2008; 54: 23-30.

77. Maccarrone M, Fiori A, Bari M, Granata F, Gasperi V, De Stefano ME, et al. Regulation by cannabinoid receptors of anandamide transport across the blood-brain barrier and through other endothelial cells. Thromb Haemost 2006; 95: 117-127.

78. Thors L, Fowler CJ. Effect of nitric oxide donors on membrane tritium accumulation of endocannabinoids and related endogenous lipids. Eur J Pharmacol 2009; 621: 10-18.

79. Stefano GB, Salzet B, Rialas CM, Pope M, Kustka A, Neenan K, et al. Morphine- and anandamide-stimulated nitric oxide production inhibits presynaptic dopamine release. Brain Res 1997; 763: 63-68.

80. Spina E, Trovati A, Parolaro D, Giagnoni G. A role of nitric oxide in WIN 55,212-2 tolerance in mice. Eur J Pharmacol 1998; 343: 157-163.
81. Azad SC, Marsicano G, Eberlein I, Putzke J, Zieglgansberger $W$, Spanagel R, et al. Differential role of the nitric oxide pathway on delta(9)-THC-induced central nervous system effects in the mouse. Eur J Neurosci 2001; 13: 561-568.

82. Waksman Y, Olson JM, Carlisle SJ, Cabral GA. The central cannabinoid receptor (CB1) mediates inhibition of nitric oxide production by rat microglial cells. J Pharmacol Exp Ther 1999; 288: 1357-1366.

83. Rawls SM, Tallarida RJ, Gray AM, Geller EB, Adler MW. LNAME (N omega-nitro-L-arginine methyl ester), a nitric-oxide synthase inhibitor, and WIN 55212-2 [4,5-dihydro-2-methyl4(4-morpholinylmethyl)-1-(1-naphthalenyl-carbonyl)-6 $\mathrm{H}$-pyrrolo[3,2,1ij]quinolin-6-one], a cannabinoid agonist, interact to evoke synergistic hypothermia. J Pharmacol Exp Ther 2004; 308: 780-786.

84. Hillard CJ, Muthian S, Kearn CS. Effects of CB(1) cannabinoid receptor activation on cerebellar granule cell nitric oxide synthase activity. FEBS Lett 1999; 459: 277-281.

85. Kim SH, Won SJ, Mao XO, Ledent C, Jin K, Greenberg $D A$. Role for neuronal nitric-oxide synthase in cannabinoidinduced neurogenesis. J Pharmacol Exp Ther 2006; 319: 150-154.

86. Lisboa S, Magesto AC, Resstel LB, Guimarães FS. Functional interaction between anadamide and neuronal nitric oxide synthase in the dorsolateral periaqueductal grey of rats induces complex modulation of anxiety-like behavior. Neuroscience Meeting 2011. Washington: 2011. p 123 (Abstract).

87. Cella M, Leguizamon GF, Sordelli MS, Cervini M, Guadagnoli T, Ribeiro ML, et al. Dual effect of anandamide on rat placenta nitric oxide synthesis. Placenta 2008; 29: 699707.

88. Ching LC, Kou YR, Shyue SK, Su KH, Wei J, Cheng LC, et al. Molecular mechanisms of activation of endothelial nitric oxide synthase mediated by transient receptor potential vanilloid type 1. Cardiovasc Res 2011; 91: 492-501.

89. Zschenderlein C, Gebhardt C, von Bohlen Und Halbach O, Kulisch C, Albrecht D. Capsaicin-induced changes in LTP in the lateral amygdala are mediated by TRPV1. PLoS One 2011; 6: e16116. 